\title{
Holoprosencephaly, proboscis and anophthalmia in a foetus with matUPD14 and trisomy 13. First case to be diagnosed with hysteroscopy: A case report
}

\author{
Lalou Iliana ${ }^{1}$, Gkrozou Fani ${ }^{2 *}$, Eleftherios Meridis ${ }^{3}$, Tsonis Orestis ${ }^{3}$, Paschopoulos Minas ${ }^{3}$ and Syrrou Marika $^{1}$ \\ ${ }^{1}$ Genetics Unit, Department of General Biology, Medical School, University of Ioannina, Ioannina, Greece \\ ${ }^{2}$ Department of Obstetrics and Gynaecology, University Hospitals of Birmingham, United Kingdom \\ ${ }^{3}$ Department of Obstetrics and Gynaecology, Medical School, University of Ioannina, Ioannina, Greece
}

\begin{abstract}
Introduction: Holoprosencephaly is a complex human brain malformation, which can result from incomplete cleavage of the prosencephalon into right and left hemispheres, occulting between the $18^{\text {th }}$ and the $28^{\text {th }}$ day of gestational age.

Case report: It is about a 32 years old lady. The scan of 12 weeks revealed the presence of brain abnormalities. The couple decided to terminate the pregnancy and fa fetoscopy followed, where the foetal characteristics could be identified in real time inside the uterus. Array CGH confirmed trisomy 13 and molecular analysis recognised matUPD14 in chromosome 14 and region $14 \mathrm{q} 12$.

Discussion: It is the first case where holoprosencephaly, proboscis and anophthalmia have been recognised in a foetus with matUPD14 and trisomy 13 . In addition, these characteristics were confirmed in real time by fetoscopy. It is necessary to expand our knowledge on chromosomes and develop new techniques in order to identify genetic variability.
\end{abstract}

\section{Introduction}

Holoprosencephaly (HPE, MIM 236100) is a complex human brain malformation characterised by defects of the mid forebrain and face resulting from incomplete cleavage of the prosencephalon into right and left hemispheres, occurring between the 18th and the 28th day of gestational age. The frequency of HPE is 1 in 250 pregnancies and 1 in 16,000 live births [1].

HPE is commonly categorised into three types, based on the severity of incomplete cleavage of mid forebrain: alobar, semi lobar, and lobar. Lobar HPE, where the right and left ventricles are separated, but with some continuity across the frontal cortex; semi lobar with a partial separation, and the most severe form, alobar HPE, with a single brain ventricle and no interhemispheric fissure. Another milder subtype of HPE called the middle interhemispheric variant (MIHF) or syntelencephaly, has now been recognised $[2,3]$.

In most severe cases the forebrain malformations are generally associated with facial anomalies, ranging from anophthalmia, cyclopia (one eye) or proboscis (prominent nose) to midline cleft lip, a simple hypertelorism or even no anomalies in less severe HPE forms [1]. The HPE phenotypic spectrum also encompasses microforms including facial midline anomalies with a normal brain. This wide spectrum can be observed within the same family.

Chromosomal abnormalities are observed in approximately $45 \%$ of all sporadic cases of HPE [1]. HPE can be due to chromosomal abnormalities, with a higher prevalence observed in trisomy $13(75 \%)$, triploid (20\%), and trisomy 18 (1-2\%) of cases [4,5]. HPE has also been reported in patients with trisomies other than trisomies 13 and 18, including a small number with trisomy 21 [4-9]. Analysis of recurrent chromosomal anomalies led to the identification of 12 candidate regions (named HPE1 to HPE12) on 11 chromosomes that may contain genes involved in HPE [1,2].

The term uniparental disomy (UPD) was first introduced by Engel in 1980. UPD is the presence of both copies of a chromosome, or part of a chromosome, from only one parent and with the subsequent absence of the corresponding copies from the other10. Maternal uniparental disomy (matUPD) is the presence of both maternal chromosomes and absence of paternal contribution and respectively patUPD happens when the two inherited chromosomes derive only from father.

Uniparental disomy (UPD) of chromosome 14 causes multiple congenital anomalies and has been most commonly identified in individuals having two maternally derived copies (UPD (14) mat). These individuals have certain phenotypic characteristics, including intrauterine growth retardation, short stature, scoliosis, hypotonia, obesity, distinctive facial appearance, mental delay, developmental delay, and precocious puberty $[11,12]$.

We report a rare case of facial features of HPE associated with matUPD14 in region 14q12 and trisomy 13.

${ }^{\star}$ Correspondence to: Fani Gkrozou, Obstetrics and Gynaecology, $\mathrm{MD}, \mathrm{PhD}$ University Hospitals of Birmingham, United Kingdom, E-mail: fani.gkrozou@ nhs.net

Key words: holoprosencephaly, proboscis, anophthalmia, trisomy 13, matUPD14 Received: April 01, 2019; Accepted: April 23, 2019; Published: April 29, 2019 
Iliana L (2019) Holoprosencephaly, proboscis and anophthalmia in a foetus with matUPD14 and trisomy 13. First case to be diagnosed with hysteroscopy: A case report

\section{Case report}

It is about a 32 years old woman, gravida 2 and para 1, who had one previous delivery with caesarean section three years ago. Her menstrual cycle was bigger than 35 days. She had polycystic ovarian syndrome, otherwise she was fit and well, without any other medical or family history.

It was a low risk pregnancy. Dating scan was normal and all the screening blood test was normal too. At the $12^{\text {th }}$ week, the ultrasound revealed the characteristics of HPE. More specific, there was a single cystic cavity between the two hemispheres in the anterior part of the skull. In addition, there was an absence of the midline echo and cavum pellucid. A coronal scan through the head showed varying degrees of thalamic fusion. Apart from the HPE, ultrasound showed anophthalmia, proboscis, cystic skull, abnormal hands and genitals too. The couple decided to terminate the pregnancy. In addition, a diagnostic hysteroscopy (fetoscopy) performed, which gave more information about the phenotype of the foetus in real time (Figures 1 and 2). In these pictures proboscis is very easy to be identified, such as the anophthalmia and the cystic skull.

\section{Results}

Array CGH result: trisomy $13(47, \mathrm{XX}+13)$ (Figure 3)

Molecular analysis with polymorphic markers results: matUPD14 in chromosome 14 and region 14q12 (Figure 4).

\section{Discussion}

The causes of HPE are diverse. The most cases are sporadic chromosomal abnormalities (usually trisomy 13) or an autosomalrecessive disease (Meckel- Gruber syndrome), but in the majority of cases the cause is unknown. Concerning embryology, the complex cerebral developmental abnormality is based on incomplete cleavage of prosencephalon, resulting in brain malformations in addition to various facial anomalies.

The abortive foetus was examined with molecular analysis with polymorphic markers for chromosome 14 and revealed matUPD14 in region $14 \mathrm{q} 12$ of chromosome 14 . The association of human chromosome 14 with HPE originates from reported cases of patients diagnosed with HPE and with a chromosome 14 aberration [13]. Levin and Surana reported the first case of HPE associated with proximal interstitial

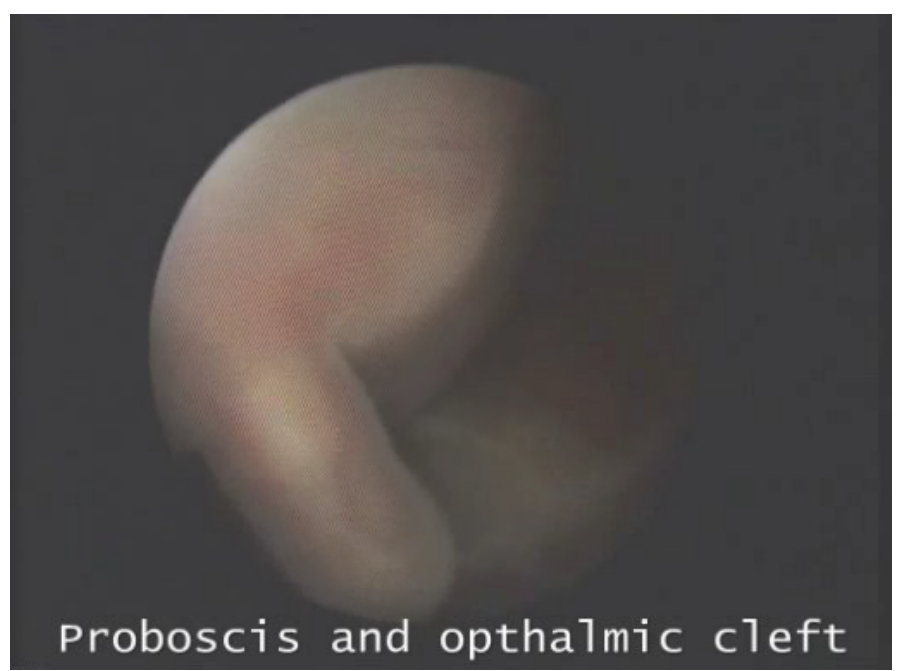

Figure 1. Hysteroscopic imaging of fetal proboscis and ophthalmic cleft

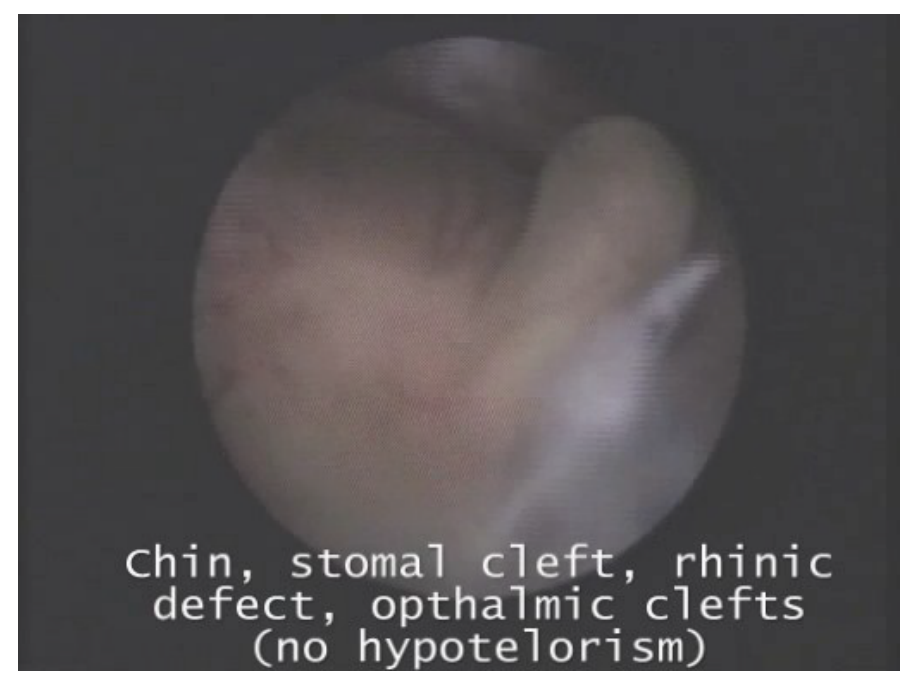

Figure 2. Hysteroscopic imaging of fetal chin, stomal cleft, rhinic defect, ophthalmic clefts

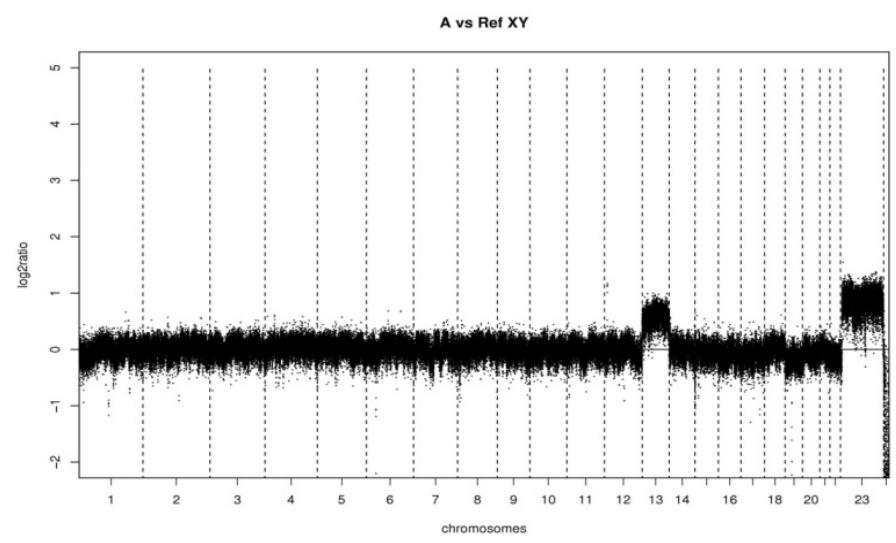

Figure 3. Array CGH result: trisomy $13(47, \mathrm{XX}+13)$
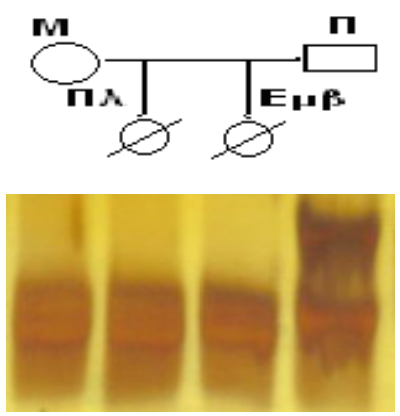

Figure 4. Molecular analysis with polymorphic markers result: matUPD14 in chromosome 14 and region $14 \mathrm{q} 12$

deletion of chromosome 14, del (14) (q11.1q13), in 1991 [14]. Chen et al. have presented a foetal case of de novo proximal interstitial deletion of chromosome 14, del (14) (q13q21.1) associated with cynocephaly, alobar HPE, and microcephaly [14-16]. These cases with proximal interstitial deletion of $14 \mathrm{q}$ suggest that chromosomal band $14 \mathrm{q} 13$ may be associated with foetal craniofacial development and HPE [1].

This is the first case of a fetus with HPE and matUPD14 reported to the literature so far. Our result suggests that probably the region $14 \mathrm{q} 12$, which is very close to the region $14 \mathrm{q} 13$, may be associated with HPE. MatUPD14 consists with both maternal chromosomes and absence of paternal contribution. So is logical to say that we have duplication of 
Iliana L (2019) Holoprosencephaly, proboscis and anophthalmia in a foetus with matUPD14 and trisomy 13. First case to be diagnosed with hysteroscopy: A case report

the maternal region but also deletion of the paternal region. If there are imprinted genes, which are expressed only from the paternal chromosome, and there are responsible for the well function and development of the brain, then that function is going to be lost with the substantial deletion of the paternal region.

In the region $14 \mathrm{q} 12$, the FOXG1 gene is present. It is the transcription repression factor, which plays an important role in the establishment of the regional subdivision of developing brain and in the development of the telencephalon. Duplication of that region has as result the presence of Rett syndrome with others mental and brain characteristics, but deletion of the region containing FOXG1 includes postnatal microcephaly, severe intellectual disability with absence of language and agenesis of the corpus callosum. When it is associated with large 14q12q13 deletions, patients present with facial dysmorphe [18-20]. So, the gene dosage of FOXG1 appears to be critical for the normal development of brain.

To confirm the molecular analysis result, the abortive material was sent to second evaluation with the technique of Array Comparative Genomic Hybridization (Array CGH). The Array CGH analysis revealed trisomy $13(47, \mathrm{XX}+13)$.

Trisomy 13, which was first described by Patau et al. in 1960, is the third most common trisomy, after trisomies 21 and 18. The condition is lethal, and the rate of miscarriage or foetal death between 12 and 40 weeks of gestation is approximately $80 \%$. The median survival time for children who are born with this disorder is 7 days, and only $5 \%$ of infants survive to the end of the first year [3].

Trisomy 13 accounts for up to $75 \%$ of cases of patients with HPE due to all chromosomal anomalies (including cryptic rearrangements) and triploid for up to $20 \%$, while trisomy 18 is much less commonly seen in conjunction with HPE, and accounts for $1-2 \%$ of cases [3-5].

Also, trisomy 13 and trisomy 18 are chromosomal abnormalities commonly known to be associated with bilateral anophthalmia. In these cases, anophthalmia is secondary to severe mal development and differentiation of the forebrain [21].

It is important to understand that the ultrasound or hysteroscopy (fetoscopy) can potentially add more information about the characteristics of the foetuses and play an important role at the identification of the genetic/chromosomal abnormalities. Fetoscopy is a technique that can be performed only for research purposes and only if a couple has decided the termination of the pregnancy. This is a way to collect more information about the phenotype in real time and in cases of alive foetuses. Until now, all the information for anatomy is coming from extra-uterine foetuses. Fetoscopy is the method that identifies the clinical characteristics of the foetus during their intrauterine life [22,23]. (Figures 3,4)

Clearly, HPE is a common feature of trisomy 13. HPE has been reported in $17-39 \%$ of patients with trisomy $13[6,8,23]$. While HPE due to trisomy 13 is often detected prenatally by ultrasound, this technique is obviously not as sensitive as pathologic examination. When pathological examination is performed about $67 \%$ of patients with trisomy 13 have signs of forebrain anomalies consistent with HPE [9]. It is necessary to expand our knowledge on chromosomes and develop new techniques, such as to be able to recognise all the bizarre genetic cases and provide the right information to the couple and let them decide about the future of its pregnancy.

\section{References}

1. Segawa Y, Itokazu N, Hirose A, Nakagawa S, Takashima S (2007) A case of partial 14q- with facial features of holoprosencephaly and hydranencephaly. Pediatr Neurol 37: 51-54. [Crossref]

2. Dubourg C, Bendavid C, Pasquier L, Henry C, Odent S, et al. (2007) Holoprosencephaly Orphanet J Rare Dis 2: 8. [Crossref]

3. Giampiero C, Pier LC, Guido A, Erich C, Alessandra A, et al. (2006) Alobar holoprosencephaly, mobile proboscis and trisomy 13 in a foetus with maternal gestational diabetes mellitus: a $2 \mathrm{D}$ ultrasound diagnosis and review of the literature. Arch Gynecol Obstet 275: 385-387.

4. Ong S, Tonks A, Woodward ER, Wyldes MP, Kilby MD, et al. (2007) An epidemiological study of holoprosencephaly from a regional congenital anomaly register: 1995-2004; p. $340-347$

5. Goetzinger KR, Stamilio DM, Dicke JM, Macones GA, Odibo AO (2008) Evaluating the incidence and likelihood ratios for chromosomal abnormalities in fetuses with common central nervous system malformations. Am J Obstet Gynecol 199: 285. [Crossref]

6. Lehman CD, Nyberg DA, Winter TC 3rd, Kapur RP, Resta RG, et al. (1995) Trisomy 13 syndrome: prenatal US findings in a review of 33 cases. Radiology 194: 217-222. [Crossref]

7. Bullen PJ, Rankin JM, Robson SC (2001) Investigation of the epidemiology and prenatal diagnosis of holoprosencephaly in the North of England. Am J Obstet Gynecol 184: 1256-1262. [Crossref]

8. Papp C, Beke A, Ban Z, Szigeti Z, Toth-Pal E, et al. (2006) Prenatal diagnosis of trisomy 13: analysis of 28 cases. J Ultrasound Med 25: 429-435. [Crossref]

9. Benjamin DS, Kenneth NR, Jeanne MM (2010) Holoprosencephaly due to numeric chromosome abnormalities. Am J Med Genet C Semin Med Genet 154 C: 146.

10. Kotzot D (2008) Prenatal testing for uniparental disomy: indications and clinical relevance Ultrasound. Obstet Gynecol 31: 100-105.

11. Sutton VR, Shaffer LG (2000) Search for imprinted regions on chromosome 14 comparison of maternal and paternal UPD cases with cases of chromosome 14 deletion. Am J Med Genet 93: 381-387. [Crossref]

12. Kurosawa K, Sasaki H, Sato Y, Yamanaka M, Shimizu M, et al. (2002) Paternal UPD14 is responsible for a distinctive malformation complex. Am J Med Genet 110:268-272.

13. Kamnasaran D, Chih-Ping C, Koenraad D, Lakshmi M, Diane W, at al. (2005) Defining a holoprosencephaly locus on human chromosome $14 \mathrm{q} 13$ and characterization of potential candidate genes. Genomics 85: 608-621.

14. Levin SW, Surana RB (1991) Holoprosencephaly associated with 46, XX,del(14) (q11.1q13). Am J Hum Genet 49: 269.

15. Chen CP, Lee CC, Chen LF, Chuang CY, Jan SW, et al. (1997) Prenatal diagnosis of de novo proximal interstitial deletion of $14 \mathrm{q}$ associated with cebocephaly. J Med Genet 34: 777-778. [Crossref]

16. Devriendt K, Fryns JP, Chen CP (1998) Holoprosencephaly in deletions of proximal chromosome 14q. J Med Genet 35: 612. [Crossref]

17. Chen CP, Jin-Chung S, Chin-Yuan T, Schu-Rern C, Chen-Ju L, et al. (2008) Prenata visualization of cynocephaly with a prominent nose in a second trimester foetus with alobar holoprosencephaly and trisomy 13. Taiwan J Obstet Gynecol 47: 1.

18. Perche O, Haddad G, Menuet A, Callier P, Marcos M, et al. (2013) Dysregulation of FOXG1 pathway in a 14q12 microdeletion case. Am J Med Genet A 161A: 3072-3077. [Crossref]

19. Santen GW1, Sun Y, Gijsbers AC, Carré A, Holvoet M, et al. (2012) Further delineation of the phenotype of chromosome 14q13 deletions: (positional) involvement of FOXG1 appears the main determinant of phenotype severity, with no evidence for a holoprosencephaly locus. J Med Genet 49: 366-372. [Crossref]

20. Takagi M, Sasaki G, Mitsui T, Honda M, Tanaka Y, et al. (2013) A 2.0 Mb microdeletion in proximal chromosome $14 \mathrm{q} 12$, involving regulatory elements of FOXG1, with the coding region of FOXG1 being unaffected, results in severe developmental delay, microcephaly, and hypoplasia of the corpus callosum. pii: S1769-7212: 00141-00129.

21. Ahmad ME, Rima D, Tanuj D, Kiran K (2003) 14q (22) Deletion in a familial case of anophthalmia with polydactyly. American Journal of Medical Genetics 120A: 117-122.

22. Ville Y, Khalil A, Homphray T, Moscoso G (1997) Diagnostic embryoscopy and fetoscopy in the first trimester of pregnancy. Prenat Diagnosisis 17: 1237-1246. 
Iliana L (2019) Holoprosencephaly, proboscis and anophthalmia in a foetus with matUPD14 and trisomy 13. First case to be diagnosed with hysteroscopy: A case report

23. Quintero RA, Puder KS, Cotton DB (1993) Embryoscopy and fetoscopy. Obstet Gynecol Clin North Am 20: 563-581. [Crossref]
24. Lin HY, Lin SP, Chen YJ, Hsu CH, Kao HA, et al. (2007) Clinical characteristics and survival of trisomy 13 in a medical center in Taiwan, 1985-2004. Pediatr Int 49: 380386. [Crossref]

Copyright: (C2019 Iliana L. This is an open-access article distributed under the terms of the Creative Commons Attribution License, which permits unrestricted use, distribution, and reproduction in any medium, provided the original author and source are credited. 